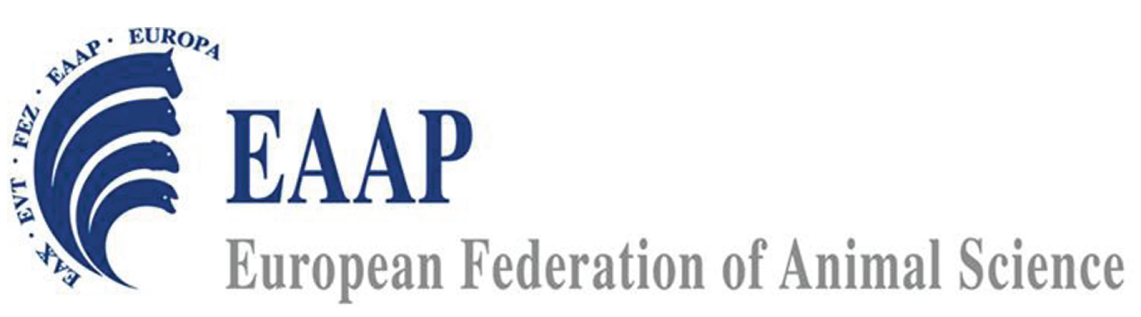

EAAP is the International Federation of Animal Science for Europe and the Mediterranean area.

Join EAAP and become member of the most exciting international animal science network and then have access to many services that are indispensible for every animal scientist worldwide

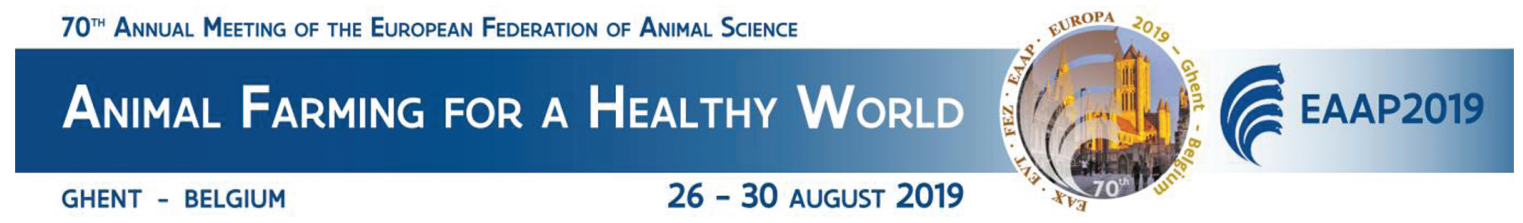

The $70^{\text {th }}$ Annual Meeting of the European Federation of Animal Science (EAAP) will be held in the historic yet contemporary city of Ghent, Belgium. The main organizer is the Flanders Research Institute of Agriculture, Fisheries and Food (ILVO) under the patronage of the Department of Agriculture and Fisheries from the Flemish Government. The conference will take place in the International Convention Centre (ICC) in Ghent. The ICC is one of the largest and most polyvalent congress centres in Belgium lying in a quiet oasis in the middle of Ghent's largest park and green lung: the Citadel Park. Gent ICC is within 15 minutes walking distance from the historical heart of Ghent and from most of the hotels.

Since 2013, Ghent's ICC yearly received the Green Key, an international quality label that recognizes exceptional corporate environ-mental efforts. ICC is centrally located near the international railway station Gent-Sint Pieters, near the access roads to the main motorways, and just 45 minutes from Brussels Airport. Gent ICC has two neighbours within the park: the world renowned SMAK or City Museum for Contemporary Art and the Museum of Fine Arts.

Belgium covers an area of $30,528 \mathrm{~km}^{2}$ and has a population of more than 11 million. It is home to the Dutch-speaking, mostly Flemish community and the French-speaking, mostly Walloon community, which constitute respectively 59 and $40 \%$ of the population. Additionally, there is a small group of German speakers, who live in the East Cantons. The capital is Brussels and other major cities are Antwerp, Ghent, Bruges, Charleroi and Liège.

In Belgium about $2 \%$ of the population is directly employed in agriculture, which accounts just under the same percentage of the nation's GDP. Agriculture in Belgium has traditionally been a family affair, but like in other West-European countries, the number of farms decreased by $30 \%$ over the last 10 years. The remaining farms are increasing in scale, improving yields and adopting new technologies.

In Flanders, agriculture is mainly intensive. Flemish farmers specialize in pig breeding, poultry and dairy farming, vegetables and fruit, ornamental plant culture. In Wallonia, the emphasis is more on arable farming (sugar beet, potatoes, barley) and extensive soil-based cattle breeding.

Livestock dominates our agriculture and accounts for $65 \%$ of the nation's farms. In 2016, our farmers housed on average 2.5 million cattle, 6.2 million pigs, 28 million broilers and 14 million laying hens. This resulted in the production of 278,000 tons of cattle meat, 3.8 million tons of milk, 89,000 tons of butter, 1.6 million tons of pig meat, 396,000 ton of poultry meat and 155,000 tons of eggs. With a self-sufficiency of $252 \%$ for pigs, $192 \%$ for poultry and $164 \%$ for cattle, export of animal products plays an important role in the agro-food industry. In 2016, we exported almost 702,000 tons of fresh and frozen pork worldwide, with a value of about 1.2 billion euros. For beef and veal, we exported a total of 150,000 tons, worth some 683 million euros. The total dairy export amounted to 3.2 billion euros, around 2.1 million tons of products and for poultry 450,000 tons was exported in 2016.

Belgium is also known worldwide for some specialties like waffles, 'French fries (which were actually invented in Belgium), beer (nearly 1,600 different kinds), chocolate and a variety of specialty cheeses.

For more information concerning this meeting, please contact:

\section{Conference Information:}

http:// www.eaap2019.org 
EAAP is also active on Social Media,

Please follow us on Facebook and Twitter Facebook:

https://www.facebook.com/EAAP.ORG
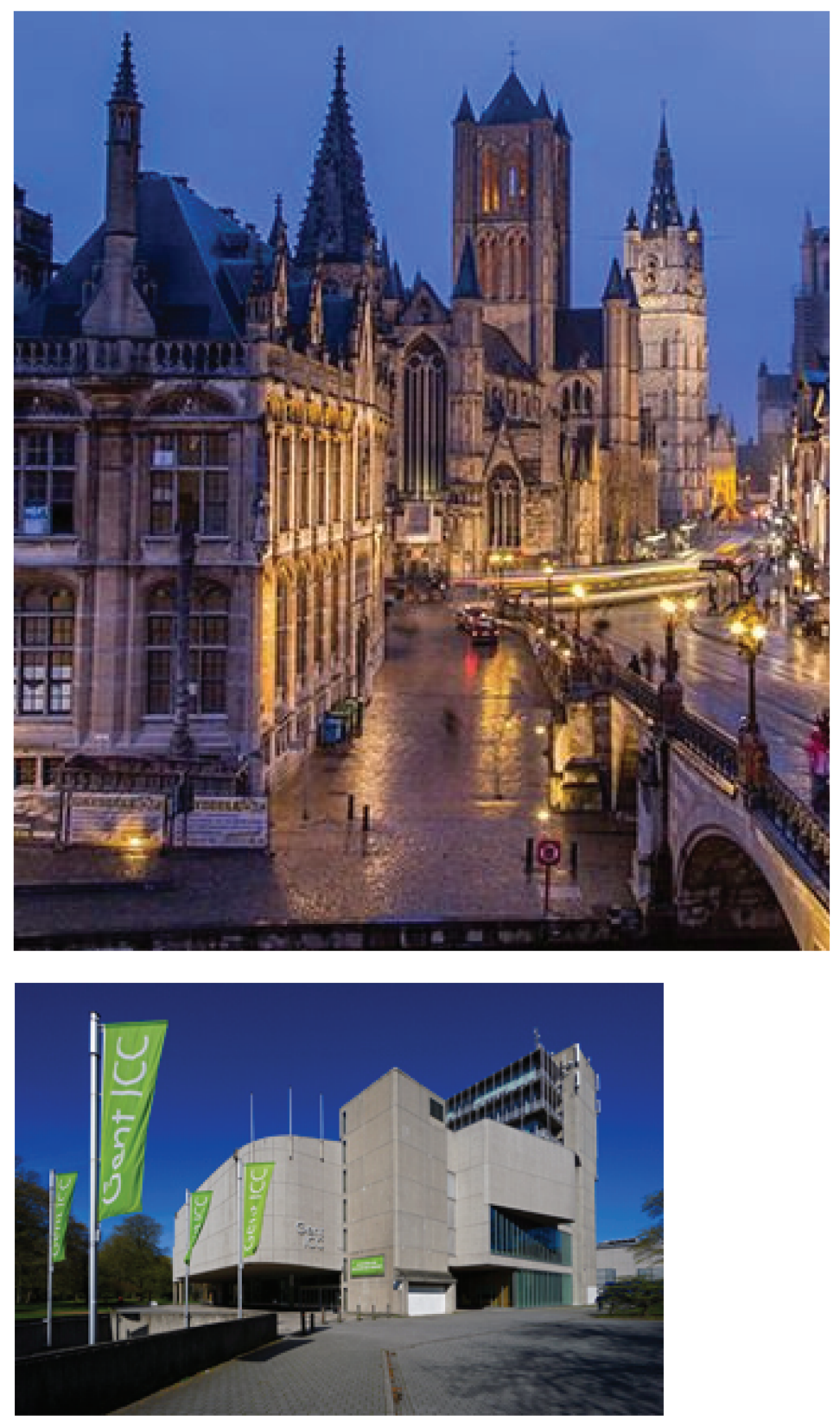

\section{INDIVIDUAL MEMBERSHIP OF EAAP}

The EAAP membership is open to all scientists. It is a great opportunity to be update on the latest publications and other relevant information in the animal sector.

We have more than 3500 members already!

It is easy to join, please contact http://www.eaap.org/Content/Individual_Member_Information.html

Membership is free of charge for most European scientists and the membership fee for scientists from non EAAP member countries is very modest. 